\title{
Challenges and successes of recruitment in the "angiotensin- converting enzyme inhibition in infants with single ventricle trial" of the Pediatric Heart Network - ERRATUM
}

\author{
Nancy A. Pike, Victoria Pemberton, Kerstin Allen, Jeffrey P. Jacobs, Daphne T. Hsu, Alan B. Lewis, \\ Nancy Ghanayem, Linda Lambert, Kari Crawford, Teresa Atz, Rosalind Korsin, Mingfen Xu, \\ Chitra Ravishankar, James Cnota, Gail D. Pearson, for the Pediatric Heart Network Investigators
}

doi:10.1017/S1047951112000832, Published by Cambridge University Press, 5 July 2012.

First published online: 10 October 2012

The labelling in Figure 1 contains two errors introduced by a typesetter. The corrected figure appears below.

The Publisher apologizes for this error.

\section{Reference}

Pike NA, Pemberton V, Allen K, Jacobs JP, Hsu DT, Lewis AB, Ghanayem N, Lambert L, Crawford K, Atz T, Korsin R, Xu M, Ravishankar C, Cnota $\mathrm{J}$, Pearson GD. Challenges and successes of recruitment in the "angiotensinconverting enzyme inhibition in infants with single ventricle trial" of the Pediatric Heart Network. Cardiol Young. Published by Cambridge University Press, 5 July 2012. doi:10.1017/S1047951112000832.

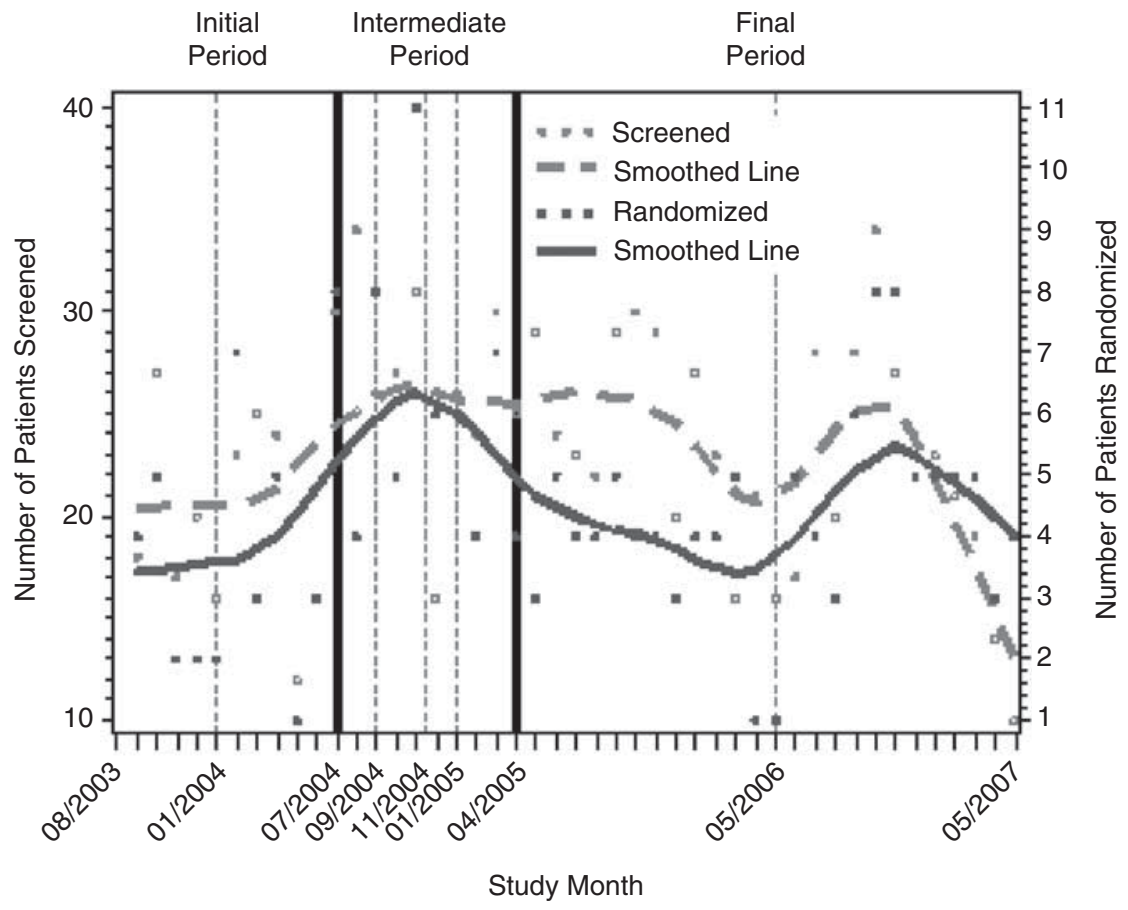

08/2003: ISV Trial Launch 01/2004: Calls with Sites 07/2004: New Strategies 09/2004: Approval of Protocol Amendment 11/2004: 3 New Sites Added
01/2005: Recruitment Call 04/2005: Surgical Trial Launch 05/2006: Coordinator Call 05/2007: ISV Recruitment Ends 